\title{
Relationship of Presympathetic-Premotor Neurons to the Serotonergic Transmitter System in the Rat Brainstem
}

\author{
ILAN A. KERMAN,* CYRUS SHABRANG, LARRY TAYLOR, HUDA AKIL, \\ AND STANLEY J. WATSON \\ Molecular and Behavioral Neuroscience Institute, University of Michigan, Ann Arbor, \\ Michigan 48109
}

\begin{abstract}
Numerous physiological conditions and emotionally motivated behaviors require concomitant activation of somatomotor and sympathetic efferents. Using a virally mediated retrograde transsynaptic tract-tracing approach, we have previously determined locations of presympathetic-premotor neurons (PSPMNs) in the rat brainstem. These putative dualfunction neurons send projections to somatomotor and sympathetic targets and likely participate in sympatho-somatomotor integration. A significant portion of these neurons is found within brainstem areas known to contain serotonergic neurons. Thus, we hypothesized that some of the PSPMNs utilize serotonin as their neurotransmitter. To test this hypothesis we first produced an antibody against TPH2, a brain-specific isoform of tryptophan hydroxylase (serotonin synthetic enzyme). We identified PSPMNs by using recombinant strains of the pseudorabies virus (PRV) for transsynaptic tract-tracing. PRV-152, a strain that expresses enhanced green fluorescent protein, was injected into sympathectomized gastrocnemius muscle, while PRV-BaBlu, which expresses $\beta$-galactosidase, was injected into the adrenal gland in the same animals. Using immunofluorescent methods we determined whether coinfected neurons expressed TPH2. Our findings demonstrate that TPH2-positive PSPMNs are present at different rostrocaudal levels of the brainstem. Just over half of them are found at the pontomedullary junction within raphe obscurus, raphe magnus, and gigantocellular nucleus pars alpha. These cells may play a role in mediating responses to acute pain stimuli and/or participate in the central control of exercise. Overactivity of these serotonergic sympatho-somatomotor circuits may also play a role in the pathophysiology of serotonin syndrome. J. Comp. Neurol. 499:882-896, 2006. ๑ 2006 Wiley-Liss, Inc.
\end{abstract}

Indexing terms: tryptophan hydroxylase; sympatho-somatomotor integration; somatomotor control; central autonomic circuits; Pseudorabies virus; ventromedial medulla

A wide range of human and animal behaviors are characterized by coordinated activation or inhibition of the activity of somatomotor efferents and that of the sympathetic nervous system. Such behaviors can be divided into several categories, including those that: 1) support daily physiological functions of the organism, 2) are part of motivated behaviors, and 3) are part of emotionally driven responses. Examples of behaviors in the first category include locomotion, exercise, cold defense, and sleep. Each of these behaviors is characterized by a specific and coordinated pattern of sympathetic and somatomotor activity. In the case of locomotion, or other forms of exercise, the onset of rhythmic somatomotor discharge is accompanied by an immediate increase in respiratory function as well as increases in heart rate, stroke volume, cardiac output, peripheral resistance, and blood pressure to improve oxygen delivery to contracting muscles (Waldrop et al., 1996). Likewise, cold defense is characterized by increased shivering together with an increase in activity of sympathetic nerves innervating brown adipose tissue (Morrison, 2004). Motivated behaviors are likewise characterized by somatomotor and autonomic activation, such as during feed-

*Correspondence to: I.A. Kerman, 205 Zina Pitcher Pl., Molecular and Behavioral, Neuroscience Institute, University of Michigan, Ann Arbor, MI 48109. E-mail: kerman@umich.edu

Received 18 April 2006; Revised 25 May 2006; Accepted 21 July 2006 DOI 10.1002/cne.21129

Published online in Wiley InterScience (www.interscience.wiley.com). 
ing behavior when activation of visceral efferents to the gut needs to be coordinated with that of the somatomotor efferents innervating muscles of mastication (Sutcliffe and de Lecea, 2000). Furthermore, emotionally motivated behaviors are characterized by concomitant recruitment of somatomotor and sympathetic efferents. For example, aggressive/defensive behavior may be characterized by hissing, alerting, turning of the head, and kicking or striking together with increases in blood pressure and heart rate as well as complementary redistribution of systemic blood flow (Mancia and Zanchetti, 1981; Hilton, 1982; Jordan, 1990).

Despite such compelling behavioral examples, traditional views on the neural control of the sympathetic and somatomotor systems have posited that these are regulated by very different neural networks. In such a scheme the somatic motor system is viewed to be largely under voluntary control and is regulated by voluntary action (Cannon, 1963). In contrast, the function of the internal viscera is viewed as largely outside of the willful control of the body and was thought to be regulated subconsciously by the sympathetic and parasympathetic arms of the autonomic nervous system (Langley, 1921; Cannon, 1963). More recent anatomical investigations have challenged this notion and have provided evidence against this arbitrary separation between somatomotor and autonomic systems. Specifically, Holstege (1995) suggested the existence of an emotional motor system, which coordinates somatic motoneuron activity as part of emotionally motivated behaviors. Work in our laboratory has sought to extend these findings by directly addressing the question of whether neurons with dual sympathetic and somatomotor functions exist. Using genetically engineered strains of the pseudorabies virus (PRV), we previously identified distinct populations of neurons that simultaneously send transsynaptic projections to the adrenal gland and the gastrocnemius muscle; populations of such cells were distributed throughout the neuraxis and included areas in the medulla, pons, midbrain, hypothalamus, and cortex (Kerman et al., 2003, 2006).

A major brainstem area containing such presympathetic-premotor neurons (PSPMNs) was located within several nuclei that comprise the ventromedial medulla, including the caudal raphe nuclei (raphe obscurus, raphe pallidus, and raphe magnus), gigantocellular nucleus pars alpha, and the ventral gigantocellular nucleus (Kerman et al., 2003). These ventromedullary nuclei contain large numbers of serotonergic neurons that send descending projections to the spinal cord (Mason, 2001). More rostrally, we identified another major cluster of PSPMNs in the caudal portion of the ventrolateral periaqueductal gray (Kerman et al., 2006). Similar to the ventromedial medulla, this area has also been reported to contain a population of serotonergic neurons (Steinbusch, 1981).

Taken together, these observations suggest that a subset of the PSPMNs in the brainstem may use serotonin as their neurotransmitter. To test this hypothesis we utilized a previously developed paradigm for the identification of PSPMNs by using virally mediated transsynaptic tract tracing (Kerman et al., 2003, 2006) together with immunofluorescent detection of tryptophan hydroxylase (TPH), a key synthetic enzyme in the production of serotonin (Nestler et al., 2001). Two isoforms of TPH have been described, TPH1 and TPH2 (Walther et al., 2003); only the latter is expressed in the brain (Patel et al., 2004). Thus, to test our hypothesis we generated an antibody specific for TPH2.

\section{MATERIALS AND METHODS}

All of the procedures regarding animal use in this study conformed to the Guide for the Care and Use of Laboratory Animals (1996, National Academy of Sciences) and were approved by the University of Michigan's University Committee on Use and Care of Animals.

\section{Design and characterization of the TPH2 antibody}

Our initial experiments were aimed at designing an antibody against TPH and then validating the specificity of its binding in paraformaldehyde-fixed rat tissue. The TPH1 isoform is preferentially expressed in the periphery and the pineal gland, while TPH2 is expressed within the brainstem raphe nuclei (Walther et al., 2003; Patel et al., 2004). To avoid crossreactivity with other hydroxylases, our antibody was designed specifically to avoid the active core of TPH2. Instead, it targeted a unique span of the N-terminal region: Phe-Ser-Leu-Asp-Ser-Ala-Val-ProGlu-Glu-His-Gln, which was crosslinked to thyroglobulin using glutaraldehyde. The antibody was raised by injection of the conjugated peptide into a rabbit. Serum was then collected and booster inoculations were administered every 6 weeks. The current experiments were carried out with serum obtained from the sixth bleed, which was affinity-purified. Specificity of the rabbit anti-TPH antibody was confirmed in adult male Sprague-Dawley rats ( $\mathrm{n}=2$; Charles River Laboratories, Wilmington, MA). In these experiments the animals were deeply anesthetized with 1-1.5 mL intraperitoneal (i.p.) of $50 \mathrm{mg} / \mathrm{mL}$ pentobarbital sodium solution. Rats were then transcardially perfused with 100-150 mL of physiological saline followed by $400-500 \mathrm{~mL}$ of Zamboni's fixative (1.8\% paraformaldehyde, $0.075 \%$ of picric acid in $0.17 \mathrm{M}$ phosphate buffer, PB). Brains were then extracted, $10-\mu \mathrm{m}$ brain sections were cut on a cryostat at $-20^{\circ} \mathrm{C}$, and mounted on Superfrost slides (Fisher Scientific, Pittsburgh, PA) immediately after sectioning. TPH2 antibody was reacted with the tissue at multiple concentrations and the optimal dilution was empirically determined. Using the nickelenhanced horseradish peroxidase diaminobenzidine visualization procedure the optimal dilution of the antibody was 1:2,000. The distribution pattern of TPH2 immunoreactivity was examined under control conditions and under conditions when the antibody was preincubated with various peptides. In these experiments adjacent sections were incubated with the TPH2 antibody and with the TPH2 antibody solution preincubated with $2 \mu \mathrm{M}$ and $5 \mu \mathrm{M}$ of the TPH2 peptide (see sequence above). In similar experiments, adjacent sections were incubated the TPH2 antibody and with the TPH2 antibody solution preincubated with $2 \mu \mathrm{M}$ and $5 \mu \mathrm{M}$ of TPH1 peptide (Met-Ile-Glu-AspAsn-Lys-Glu-Asn-Lys-Asp-His-Ser-Leu-Glu-Arg) or preincubated with $1 \mu \mathrm{M}$ or $50 \mu \mathrm{M}$ of Ki-67 (Thr-Pro-Lys-GluLys-Ala-Gln-Ala-Leu-Glu-Asp-Leu-Ala-Gly-Phe-Lys-GluLeu-Phe-Gln-Thr-Pro), an unrelated peptide.

To determine the fraction of TPH2-positive cells within the different nuclei, one adult male Sprague-Dawley rat was deeply anesthetized with $1 \mathrm{~mL}$ i.p. of $50 \mathrm{mg} / \mathrm{mL}$ pen- 
tobarbital sodium solution and then transcardially perfused with $150 \mathrm{~mL}$ of physiological saline followed by 500 $\mathrm{mL}$ of a $4 \%$ paraformaldehyde solution containing $1.4 \%$ L-lysine and $0.2 \%$ sodium meta-periodate (PLP fixative) (McLean and Nakane, 1974). The brain was then extracted, postfixed overnight, immersed in 30\% sucrose until it sank, and cut on a freezing microtome at a thickness of $40 \mu \mathrm{m}$. A 1 -in- 6 series was then reacted with the TPH2 antibody at a concentration of 1:2,000 overnight and visualized with diaminobenzidine. The sections were then mounted on glass slides, counterstained with cresyl violet, dehydrated in graded alcohols, defatted in xylene, and coverslipped with Permount (Fisher Scientific).

\section{Overview of tract-tracing studies}

Male Sprague-Dawley rats $(\mathrm{n}=6)$ (Charles River Laboratories, Wilmington, MA) were used in tract-tracing studies. In these experiments we employed transgenic recombinants of an attenuated PRV strain, PRV-Bartha, for transneuronal tracing of multisynaptic pathways innervating adrenal gland and gastrocnemius muscle. PRV has preferential tropism for axonal terminals (Vahlne et al., 1978, 1980). It is transported in the retrograde direction from the terminals to the cell body where the viral genome is replicated in the nucleus (Enquist et al., 1998). Capsids are assembled and filled with viral DNA in the nucleus, acquire the mature envelope from a late Golgi compartment, and are transported to sites of afferent synaptic contact where cell-to-cell retrograde transneuronal transmission of infection occurs (Card et al., 1993; Enquist et al., 1998). The two viral recombinants that we employed were PRV-152 and PRV-BaBlu. Both are derived from PRV-Bartha, which is an attenuated form of the parental strain, PRV-Becker. PRV-BaBlu contains the lac Z gene at the gG locus and produces $\beta$-galactosidase ( $\beta$-gal) under the control of the viral gG promoter (Kim et al., 1999). PRV-152 carries the gene coding for enhanced green fluorescent protein (eGFP) at the gG locus, which is constitutively expressed under control of the cytomegalovirus immediate early promoter (Smith et al., 2000). Previous studies have demonstrated that PRV-152 and PRV-BaBlu are transported transsynaptically in a retrograde manner, similar to PRV-Bartha, and that the two recombinants are capable of simultaneously coinfecting the same neuronal population (Standish et al., 1995; Billig et al., 1999, 2000, 2001; Smith et al., 2000; Kerman et al., 2003, 2006).

We previously reported a robust negative correlation between an animal's weight and efficiency of infection of gastrocnemius motoneurons, with the largest rate of motoneuron infection in rats of intermediate size that weigh $\sim 200$ g (Kerman et al., 2003). Thus, animals in the current study were selected to weigh between 163 and $240 \mathrm{~g}$ for an average of $194 \pm 13 \mathrm{~g}$ (mean \pm SEM; weighed at time of sympathectomy (see below)). Animals were anesthetized with $5 \%$ isoflurane vaporized in $1-1.5 \mathrm{~L} / \mathrm{min}$ of $\mathrm{O}_{2}$, and maintained with a $1.5-2.5 \%$ concentration. Once a surgical plane of anesthesia was achieved such that there was no spontaneous movement and there were no withdrawal responses to tail and/or foot pinch, hindlimb sympathectomy was performed.

In addition to somatic motor efferents, the hindlimb is also innervated by sympathetic efferents that project to blood vessels, sweat glands, and other smooth muscle targets (Jänig and McLachlan, 1992). To prevent infection of sympathetic pathways following injection of PRV-152 into the gastrocnemius muscle, the hindlimb was surgically sympathectomized in all animals using a previously described approach (Kerman et al., 2003). Briefly, the lumbar sympathetic nerve was dissected via a ventral laparotomy and was extirpated from the level of the renal artery caudal to the bifurcation of the abdominal aorta. Neural plexuses running along the descending aorta and inferior vena cava were also stripped off under microscopic observation using fine forceps. The abdominal aorta and the inferior vena cava were then swabbed with 10-20\% phenol dissolved in ethylene glycol. The abdominal musculature was closed with sutures and the overlying skin was closed with surgical staples. This procedure is effective at removing the large majority of sympathetic efferents to the hindlimb, as evidenced by the lack of infection in the intermediolateral cell column in the same animals that exhibited robust infections of lumbar motoneurons (Kerman et al., 2003, 2006).

Following sympathectomy and a $2-10$ day recovery period the animals were reanesthetized. Due to supply problems some of the animals $(\mathrm{n}=2)$ were anesthetized with an i.p. injection of ketamine and xylazine mixture (60 $\mathrm{mg} / \mathrm{kg}$ ketamine and $7 \mathrm{mg} / \mathrm{kg}$ xylazine), while the remaining animals were anesthetized using an isoflurane protocol as described above. After a surgical plane of anesthesia was achieved the animals were injected with PRV-152 into their gastrocnemius muscle.

Following PRV-152 injections and a 24-32-hour recovery period the same rats were reanesthetized with either isoflurane $(n=4)$ or a ketamine and xylazine mixture $(\mathrm{n}=$ 2) and were injected with PRV-BaBlu into the adrenal glands. Choice of anesthetic regime had no effect on viral infection or transport.

At the conclusion of the survival period following transport of viral tracers, animals were deeply anesthetized with $1 \mathrm{~mL}$ i.p. of $50 \mathrm{mg} / \mathrm{mL}$ pentobarbital sodium solution and transcardially perfused with $100-150 \mathrm{~mL}$ of physiological saline followed by $400-500 \mathrm{~mL}$ of PLP fixative.

\section{Double-virus injections}

Viral recombinants used in the present studies were harvested from pig kidney cell cultures at a titer of $10^{8}$ $10^{9} \mathrm{pfu} / \mathrm{mL}$. Viral stocks were aliquoted in $50-\mu \mathrm{L}$ volumes and stored at $-80^{\circ} \mathrm{C}$. At the times of injection viral aliquots were removed from the freezer and kept on ice until immediately before injections.

To determine the location of neurons coordinating muscle contraction and autonomic activity, rats received injections of PRV-152 into their left $(n=4)$ or right $(n=2)$ gastrocnemius muscle and injections of PRV-BaBlu into their left adrenal gland $(n=6)$. The gastrocnemius muscle was injected with $30 \mu \mathrm{L}$ of PRV-152, which was divided into multiple injections of $1.0 \mu \mathrm{L}$. The adrenal gland was dissected via a left flank incision and gently separated from surrounding viscera and fat; the adjacent connective tissue was then retracted to facilitate access to the gland. Two or three injections of PRV-BaBlu were then made into the gland through a glass pipette attached to a $10-\mu \mathrm{L}$ Hamilton syringe; the total volume of virus injected was 2-4 $\mu \mathrm{L}$. Following each injection the gland was swabbed with a cotton-tip applicator to decrease nonspecific viral spread. We previously demonstrated that this injection protocol produces an efficient infection of target neurons and does not result in spread of virus to nontarget tissues (Kerman et al., 2003). 
Injected animals were assigned to one of three groups: short, intermediate, and long survival times. In the short survival group $(\mathrm{n}=2)$ rats survived 121-122 hours following injections with PRV-152 and 96-97 hours following PRV-BaBlu injections. We chose these survival time points because this is one of the earliest time points at which appreciable numbers of double-infected neurons are detected in the ventromedial medulla in the rat (Kerman et al., 2003, 2006). Since a single replication cycle of the virus is 10-12 hours (Demmin et al., 2001), we therefore decided to extend the survival times by 10-12 hours to determine the maximal number of double-infected neurons that express TPH2. Accordingly, in the intermediate survival group $(\mathrm{n}=2)$ the animals survived 132 and 108 hours following injections with PRV-152 and PRV-BaBlu, respectively. In the late survival group $(n=2)$ the animals survived 144 and either 112 or 120 hours following injections with PRV-152 and PRV-BaBlu, respectively.

\section{Tissue processing}

Following transcardial perfusion with PLP (see above), the entire brain was extracted and postfixed in PLP overnight. Brains were then immersed in $30 \%$ sucrose until they sank to the bottom of the container and sectioned coronally on a freezing microtome at a thickness of 35 or $40 \mu \mathrm{m}$ and collected into six bins. Tissue was stored at $-20{ }^{\circ} \mathrm{C}$ in cryoprotectant $(30 \%$ sucrose, $30 \%$ ethylene glycol, 1\% polyvinyl-pyrrolidine (PVP-40)) until immunohistochemical processing was conducted.

In two animals (both in the short survival group) thoracic and lumbar spinal cords were also collected. In these animals spinal cord was extracted in three blocks: T1-T7 segment, T8-T13, and L1-L6. These blocks were then sectioned in the horizontal plane at 35 or $40 \mu \mathrm{m}$. A onein-three series for each block was processed for simultaneous visualization of PRV-152 and PRV-BaBlu using immunofluorescent methods aimed at the detection of eGFP and $\beta$-gal (see below for methodological details).

For immunofluorescent detection in the brain, tissue was initially rinsed with $0.1 \mathrm{M} \mathrm{PB}$ ( $\mathrm{pH}$ 7.4) several times at room temperature. It was then incubated for 1 hour in a blocking solution made up of $1 \%$ normal goat serum (NGS), $1 \%$ bovine serum albumin (BSA), and $0.3 \%$ Triton X-100 (TX-100) in 0.1 M PB. Sections were then reacted with a cocktail of primary antibodies: chicken anti-GFP IgY (Abcam, Cambridge, MA, product 13970) at 1:2,000, mouse anti- $\beta$-gal IgG (Sigma, St. Louis, MO, product G4644) at 1:1,000, and rabbit anti-TPH2 at 1:500, diluted in the above blocking solution. The chicken anti-GFP antibody was raised against recombinant full-length protein. This antibody yields a single band on Western blot and detects GFP in transgenic mice expressing GFP in lamina II of the spinal cord (manufacturer's technical information). In our preliminary experiments we demonstrated the absence of staining with this antibody in uninfected rat tissue sections. Mouse anti- $\beta$-gal antibody was developed in mouse peritoneal cavities using $\beta$-gal purified from $E$. coli as the immunogen. Using Western blot, this antibody was shown to be specific for $\beta$-gal in its native form $(116 \mathrm{kD})$, and it reacts only with $\beta$-gal from $E$. coli (manufacturer's technical information). Specificity of this antibody in immunofluorescent experiments has been previously documented (Kerman et al., 2003).

Following a $24-48$-hour incubation at $4^{\circ} \mathrm{C}$ in the primary antibody solution, the tissue was rinsed several times with $0.1 \mathrm{M} \mathrm{PB}$ and then reacted with a secondary antibody solution, which consisted of donkey anti-mouse IgG conjugated to CY3 (1:200; Jackson ImmunoResearch, West Grove, PA), goat anti-chicken IgG conjugated to AlexaFluor488 (1:200; Molecular Probes, Eugene OR, Invitrogen, La Jolla, CA) and biotinylated goat anti-rabbit IgG (Vector Laboratories, Burlingame, CA) dissolved in the blocking solution (1\% NGS, $1 \%$ BSA, and $0.3 \%$ TX100). Tissue sections were then briefly rinsed and then incubated with NeutrAvidin conjugated to AlexaFluor350 (1:200; Molecular Probes, Invitrogen). Thus, PRV-152infected cells appeared green, those infected with PRVBaBlu were red, while TPH2-positive neurons were blue. Neurons double-infected with PRV-152 and PRV-BaBlu appeared either yellow or orange, depending on the balance of colors. Double-infected cells that colocalized with TPH2 would theoretically be white, since blue, green, and red represent the full spectrum of visible light. However, because of the differences in the balance and intensity of each color, triple-labeled cells were close to white in color with a bluish, reddish, or greenish tinge to them. Following processing, tissue sections were mounted on glass slides and coverslipped with Aqua Poly/Mount (Polysciences, Warrington, PA).

For immunofluorescent detection in the spinal cord a similar protocol was used. Tissue was initially rinsed with $0.1 \mathrm{M}$ PB several times at room temperature. It was then incubated for 1 hour in a blocking solution made up of $1 \%$ normal donkey serum, $1 \%$ BSA, $0.3 \%$ TX-100 in $0.1 \mathrm{M} \mathrm{PB}$. The tissue was then reacted with a cocktail of primary antibodies: rabbit anti-GFP IgG (Molecular Probes) at $1: 1,000$ and mouse anti- $\beta$-gal IgG (Sigma) at $1: 1,000$, diluted in the above blocking solution. Following a 24-48hour incubation at $4^{\circ} \mathrm{C}$ in the primary antibody solution the tissue was rinsed several times with $0.1 \mathrm{M}$ PB and then reacted with a secondary antibody solution, which consisted of donkey anti-mouse IgG conjugated to CY3 (1:200; Jackson ImmunoResearch) and goat anti-rabbit IgG conjugated to BODIPY FL (1:200; Molecular Probes) dissolved in the blocking solution. Thus, PRV-152-infected cells appeared green, while those infected with PRVBaBlu were red. Specificity of the primary and secondary antibodies employed in these double-labeling experiments has been previously documented (Billig et al., 2000; Kerman et al., 2003).

\section{Tissue analysis}

Tissue was examined using a Leica DMR photomicroscope (Wetzlar, Germany). The rat atlas of Paxinos and Watson (1986) was used as a reference for anatomical classification. Infected neurons were digitized using a Photometrics CoolSNAP $_{\mathrm{fx}}$ black-and-white camera (Tucson, AZ) and MCID Elite 7.0 imaging software (Imaging Research, St. Catharines, Ontario). The presence of each fluorophore was detected using specific filter sets (Chroma Technology, Brattleboro, VT) with the following respective excitation and emission ranges: AlexaFluor350: 320-400 $\mathrm{nm}$ and 410-510 nm (blue fluorescence), AlexaFluor488 and BODIPY FL: $440-520 \mathrm{~nm}$ and 500-555 nm (green fluorescence), and CY3: 535-560 nm and 545-625 nm (red fluorescence).

Adjacent black-and-white images of the region of interest were digitized under a $20 \times$ objective using a manually driven stage equipped with a Leica Sensor Control Display (Märzhäuser SensoTech, Wetzlar, Germany) to 
record stage coordinates. We took several high-power images through the region of interest. In order to visualize the entire area, high-power images were stitched together using the Photomerge function in Adobe Photoshop v. 8.0 (Adobe Systems, San Jose, CA). Each of these large stitched images corresponded to a different fluorescent filter set and was pseudocolored as follows: GFP-positive neurons, green; $\beta$-gal-containing cells, red; and TPH2positive neurons, blue. These pseudocolored images were then overlaid and colocalization of two or three fluorophores was determined by turning on and off each layer to determine the location and color of each cell.

Neurons expressing different combinations of signals and located within different brainstem nuclei were manually counted from the Photoshop files. Neurons were quantified from six different levels through medulla and midbrain at approximately $-12.7 \mathrm{~mm},-11.6 \mathrm{~mm},-11.0$ $\mathrm{mm},-10.3 \mathrm{~mm},-8.7 \mathrm{~mm}$, and $-7.8 \mathrm{~mm}$ relative to bregma. Since not every nucleus was present at each level, different numbers of sections were used to quantify the data for each nucleus. Quantification was performed from one section/animal for the caudal, dorsal, ventral, and ventrolateral subdivisions of the dorsal raphe, one section/ animal for ventrolateral periaqueductal gray, one section/ animal for the parapyramidal area, two sections/animal for raphe obscurus, three sections/animal for gigantocellular nucleus pars alpha (ventral and dorsal subdivisions), three sections/animal for raphe magnus, and four sections/animal for raphe pallidus.

To determine fractions of serotonergic cells in different nuclei, tissue in which TPH2 antibody was visualized with diaminobenzidine and counterstained with cresyl violet was used. Cell counts were performed using Stereo Investigator 6.5 software (MicroBrightField, Williston, VT) under a $40 \times$ objective. The total number of cells in each nucleus was determined by counting nuclei of all cresyl violet-stained cells and TPH2-positive profiles.

Brightness and contrast of images were optimized for presentation purposes, and figures were prepared in Photoshop.

\section{RESULTS Specificity of TPH2 antibody}

To ascertain the specificity of the TPH2 antibody used in these studies we carried out blocking studies with TPH1, TPH2, and Ki-67 peptides. Under control conditions, in the absence of peptide, there was robust labeling within the dorsal raphe (DR) in the midbrain (Fig. $1 \mathrm{~A}, \mathrm{D}, \mathrm{G}$ ) but not in the pineal gland (data not shown). This labeling was markedly attenuated when the antibody solution was preadsorbed with $2 \mu \mathrm{M}$ solution of the TPH2 peptide (Fig. 1B). The labeling was blocked entirely when the concentration of the TPH2 peptide was increased to 5 $\mu \mathrm{M}$ (Fig. 1E). In contrast, preadsorption of the antibody solution with TPH1 peptide had no effect on the signal intensity either at 2 or $5 \mu \mathrm{M}$ (Fig. 1C,F). Similarly, preadsorption with Ki-67, an unrelated peptide, had no effect on the immunocytochemical labeling within the dorsal raphe (Fig. 1H,I).

\section{Distribution of TPH2-positive neurons}

The distribution of TPH2-positive neurons was examined within the medulla, pons, and midbrain. In the me- dulla, TPH2-positive neurons were found within a midline column of cells comprised of raphe pallidus $(\mathrm{RPa})$ and raphe obscurus (ROb; Fig. 2A,B, respectively). At more rostral levels, TPH2-positive neurons appeared more laterally within raphe magnus (RMg; Fig. 2D), gigantocellular nucleus pars alpha (GiA; Fig. 2E), as well as the parapyramidal cell group (PPy; Fig. 2C), located dorsolaterally to the pyramidal tracts. Within GiA, TPH2-positive neurons were preferentially distributed along the ventral aspect of the nucleus. At the level of the pontomedullary junction, TPH2-immunoreactive neurons were found primarily within $\mathrm{RMg}$ and $\mathrm{RPa}$ (Fig. 2G) and GiA (Fig. 2F).

TPH2-immunoreactive neurons in the midbrain were concentrated primarily along the midline within DR and median raphe (MnR; Fig. 3A,C). Additionally, such neurons were also located within laterally displaced clusters within the ventrolateral periaqueductal gray (vlPAG; Fig. 3B,D).

The fraction of serotonergic neurons in each nucleus was estimated from the material in which TPH2 was visualized with diaminobenzidine and the tissue was counterstained with cresyl violet. In these experiments, the total number of cells was estimated from all detectable cresyl violet-stained nuclei. This quantification revealed considerable variability in the fraction of serotonergic neurons among the different nuclei. These values ranged from 5-33\%, depending on the nucleus (Table 1).

\section{Labeling in the spinal cord}

Labeling in the spinal cord was examined in two rats in the short survival group. The goals of these experiments were: 1 ) to verify the effectiveness of the surgical sympathectomy, and 2) to verify infection of the appropriate first-order neurons in thoracic and lumbar spinal cord. In both animals we detected infection in the ipsilateral gastrocnemius motoneurons with PRV-152 at L3-L4 levels of the spinal cord (Fig. 4A). We also observed infection of ipsilateral adrenal sympathetic preganglionic neurons within the intermediolateral cell column at mid-thoracic levels with PRV-BaBlu (Fig. 4B). There was no infection with PRV-152 in the intermediolateral cell column (Fig. $4 \mathrm{C}$ ), demonstrating the effectiveness of the surgical sympathectomy.

\section{Expression of TPH2 within PSPMNs}

As in our previous studies, we found considerable clusters of PSPMNs within the different subregions of the ventromedial medulla, including $\mathrm{ROb}, \mathrm{RMg}, \mathrm{RPa}, \mathrm{GiA}$, and PPy (Figs. 5-7). At more rostral levels, clusters of PSPMNs were also found within vlPAG and just lateral to the DR proper (Fig. 8). This basic distribution pattern was the same for animals at different survival times; however, the numbers of double-infected neurons increased with longer survival times (Figs. 6-8). Triple- and doublelabeled neurons were found throughout the brainstem and included neurons within the ventromedial medulla, pons, and caudal midbrain (Fig. 5).

To estimate whether specific nuclei may vary in their content of triple-labeled neurons, we mapped the locations of double- and triple-labeled cells in each animal at six different rostrocaudal levels (Figs. 6-8). This analysis revealed distinct clustering of neurons infected with one or both strains of PRV that also expressed TPH2. At the caudalmost level that we examined $(-12.7 \mathrm{~mm}$ from bregma), such neurons were confined primarily to $\mathrm{ROb}$ 

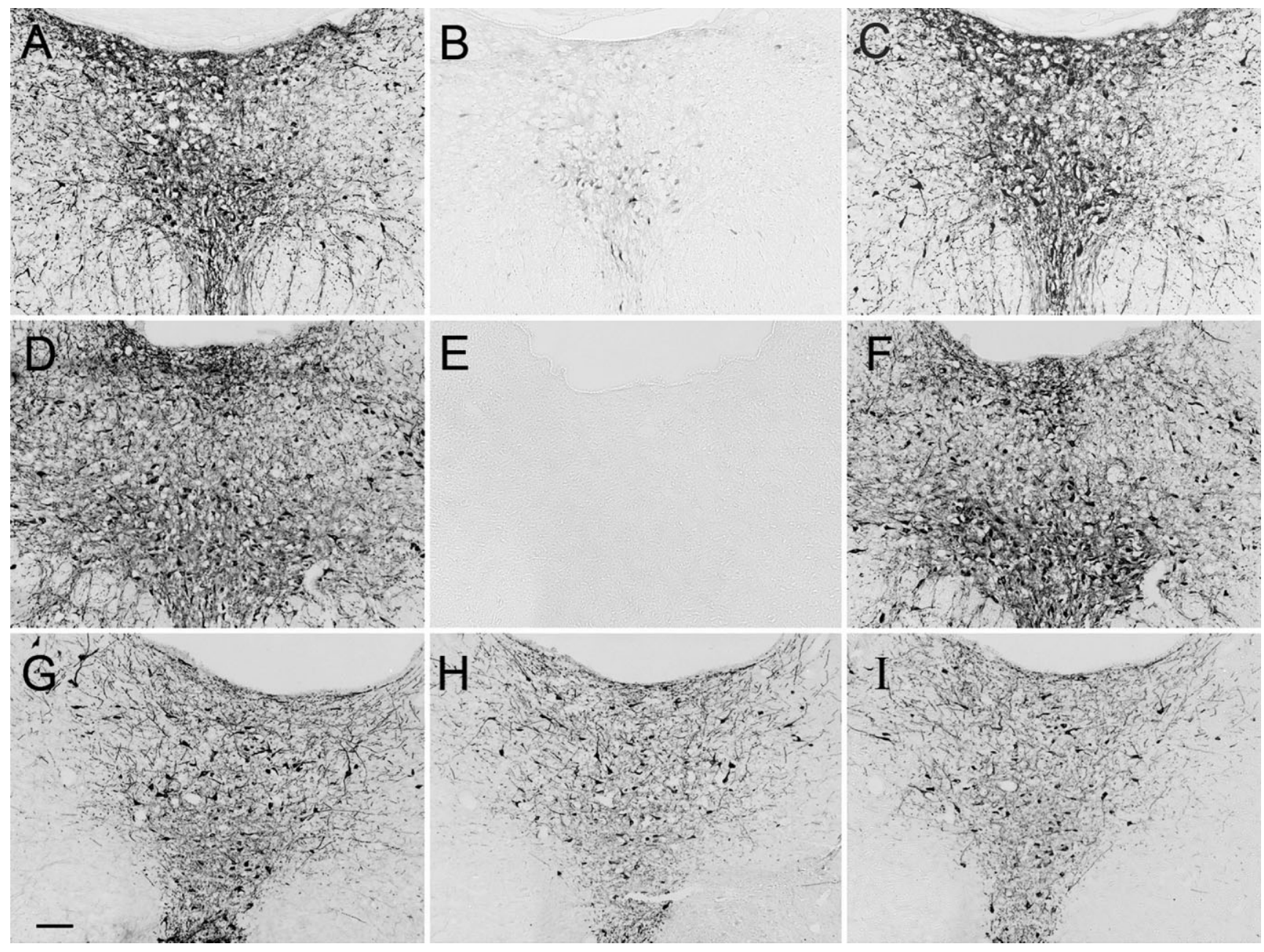

Fig. 1. Characterization of tryptophan hydroxylase 2 (TPH2) antibody. Specificity of binding was ascertained by performing a series of blocking studies. In the first experiment signal was examined under control conditions when tissue was reacted with TPH2 antibody at 1:2,000 (A). Adjacent sections were then reacted with TPH2 antibody pre-adsorbed with $2 \mu \mathrm{M}$ of either TPH2 (B) or TPH1 (C) peptide solution. In the second experiment TPH2 signal (at 1:2,000) was examined under control conditions $(\mathbf{D})$ and after preadsorption of the antibody with $5 \mu \mathrm{M}$ of either TPH2 (E) or TPH1 (F) peptide. In the last experiment TPH2 signal (at 1:2,000) was examined under control conditions $(\mathbf{G})$ and after preadsorption of the antibody with either 1 $\mu \mathrm{M}(\mathbf{H})$ or $50 \mu \mathrm{M}(\mathbf{I})$ of Ki-67 (an unrelated peptide). Scale bar $=100$ $\mu \mathrm{m}$. and distributed along the midline (Figs. 5C, 6A). At the more rostral levels within medulla-pons $(-11.6 \mathrm{~mm}$, $-11.0 \mathrm{~mm}$, and $-10.3 \mathrm{~mm}$ from bregma), these neurons fanned out laterally and ventrally and were concentrated within the ventral aspect of $\mathrm{GiA}$ and to some extent within $\mathrm{RMg}$ and PPy (Figs. 6B,D, 7). Few of the virus-infected neurons in the midbrain expressed TPH2 at the early survival times. However, at the longer survival times their numbers increased and they were displaced laterally from the midline and found predominantly within vlPAG (Fig. 8C) and lateral DR (Fig. 8D).

Estimates of the number of these cells among the different nuclei revealed differences in their distribution. At the caudal levels the greatest numbers of TPH2-positive PSPMNs were found within ROb, RMg, and GiA (Table 1). At more rostral levels, relatively low numbers of TPH2positive PSPMNs were detected in the different subdivision of DR and in the vlPAG (Table 1).
Additionally, we estimated the percentage of PSPMNs that expressed TPH2 within the different nuclei. This analysis revealed that these neurons were enriched in the ventral GiA (Table 1). In contrast, dorsal GiA contained a relatively low percentage of TPH2-positive PSPMNs (Table 1).

\section{DISCUSSION}

In the current study we focused our attention on brainstem PSPMNs. Neurons with putative dual (sympathetic and somatomotor) functions were identified by injections of distinct PRV recombinants into peripheral muscle and the adrenal gland. Based on our previous reports on the anatomical distribution of the brainstem PSPMNs, we hypothesized that a subset of them would be serotonergic. To test this hypothesis, we designed and produced an antibody against TPH2, a TPH isoform that is specifically 

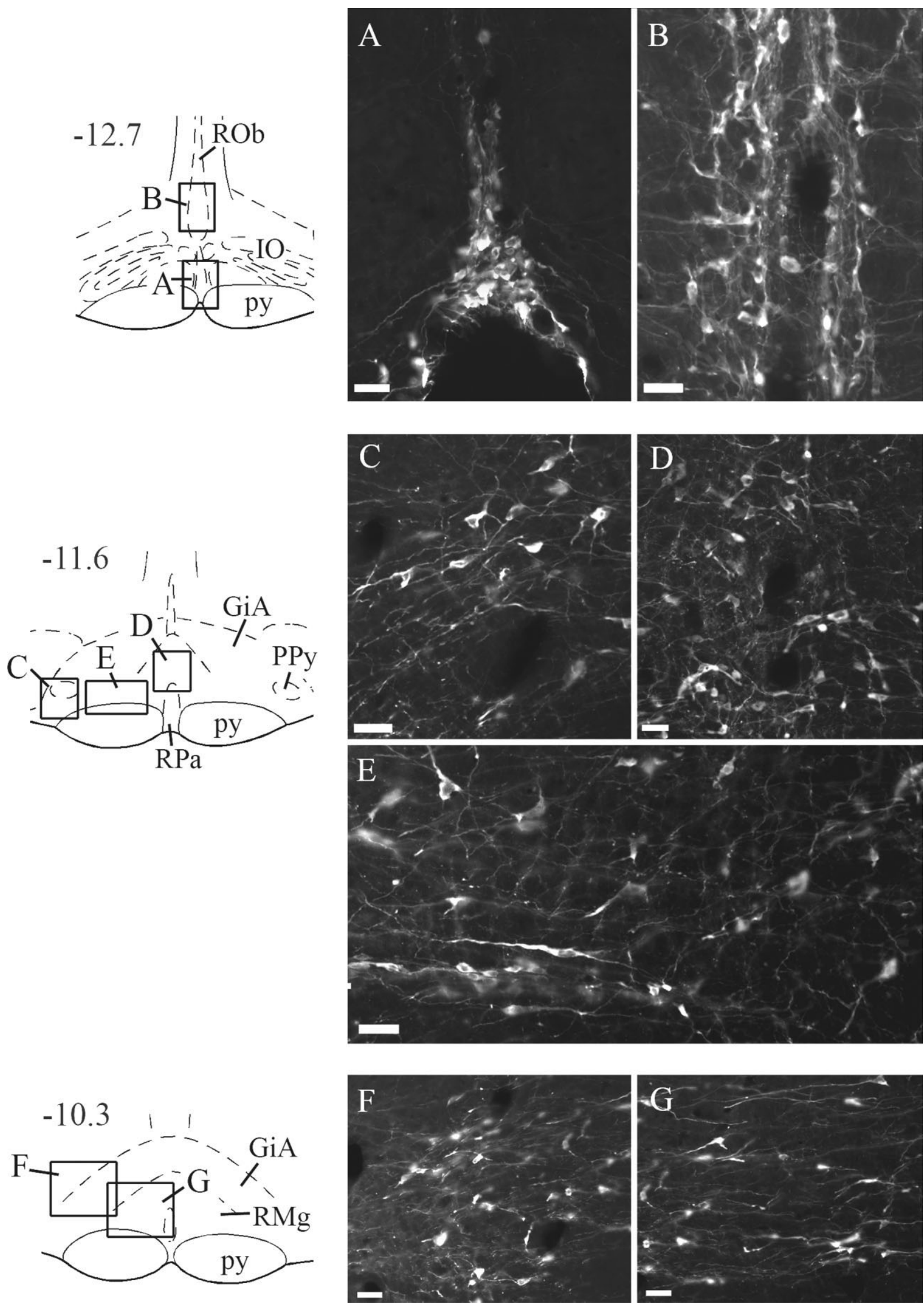

Fig. 2. Distribution of tryptophan hydroxylase-positive neurons in the medulla-pons. Drawings on the left were adapted from the Paxinos and Watson (1986) rat brain atlas and illustrate anatomical locations of photomicrographs on the right. Solid boxes in the left column correspond to panels on the right. Numbers on the left refer to approximate distance from bregma in $\mathrm{mm}$. GiA, gigantocellular nucleus pars alpha; IO, inferior olive; py, pyramidal tract; PPy, parapyramidal cell group; $\mathrm{RMg}$, raphe magnus; $\mathrm{ROb}$, raphe obscurus; $\mathrm{RPa}$ raphe pallidus. Scale bars $=50 \mu \mathrm{m}$. 

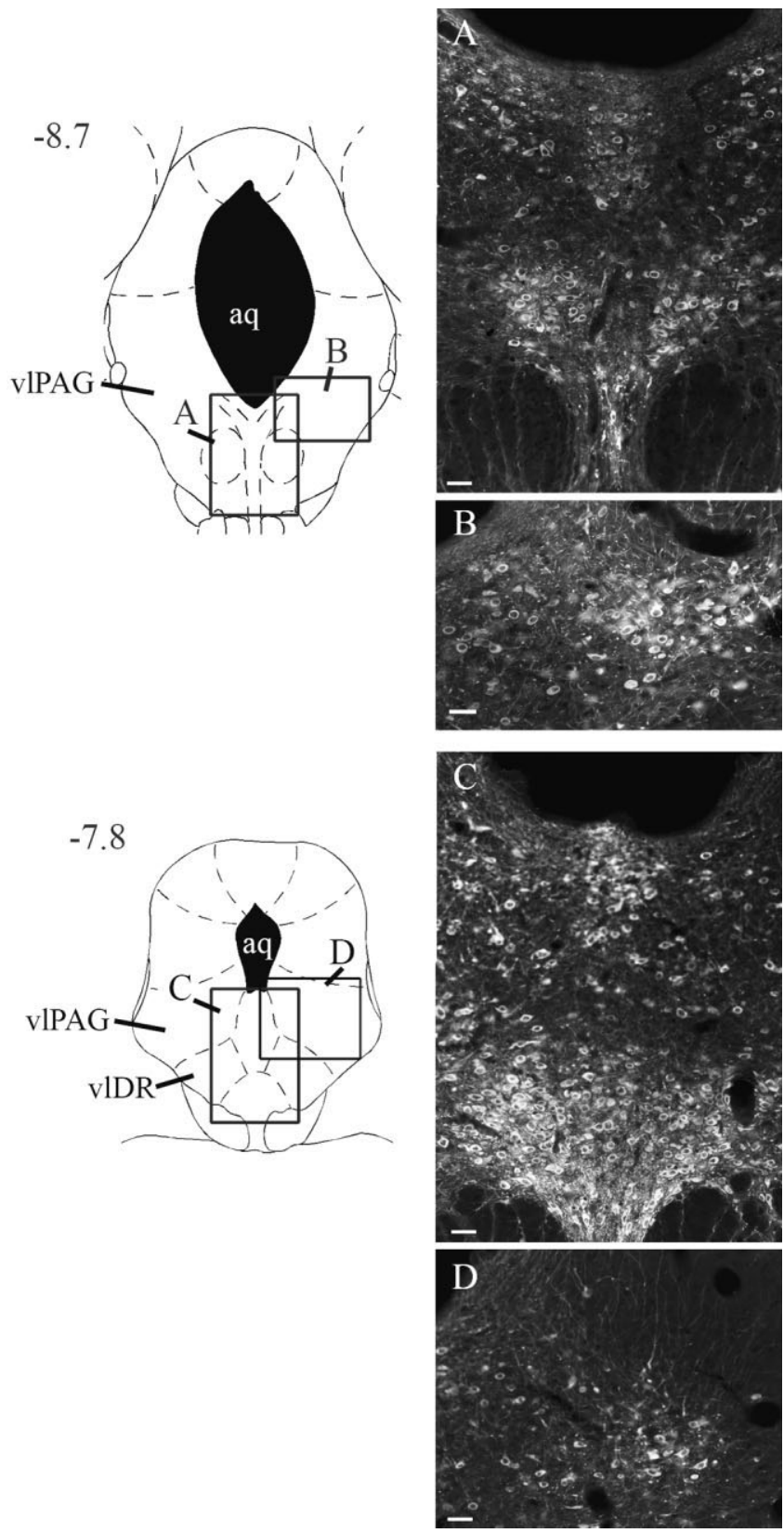

Fig. 3. Distribution of tryptophan hydroxylase-positive neurons in the midbrain. The figure layout is similar to that of Figure 2. aq, central aqueduct; vlDR, ventrolateral subdivision of the dorsal raphe; vlPAG, ventrolateral periaqueductal gray. Scale bars $=50 \mu \mathrm{m}$.

expressed in the brain (Patel et al., 2004). Our characterization studies of this antibody demonstrate that the staining produced by this antibody is specific for TPH2 since: 1 ) the signal was completely blocked by the specific TPH2 peptide but not by TPH1 or Ki-67 peptides, and 2) distribution of immunopositive neurons closely matched the distribution of TPH2 mRNA (Patel et al., 2004). Thus, we could be confident that the neurons that we detected with this antibody were serotonergic.

Our injections into the muscle and adrenal gland were effective at infecting specific first-order neurons, as dem-
TABLE 1. Fractions of Tryptophan Hydroxylase 2 (TPH2)-Positive Presympathetic-Premotor Neurons (PSPMNs), and Fractions of TPH2Positive Cells within Different Nuclei

\begin{tabular}{lcccc}
\hline & $\begin{array}{c}\text { Total } \\
\text { no. of } \\
\text { TPH2+ }\end{array}$ & $\begin{array}{c}\text { Total } \\
\text { no. of } \\
\text { PSPMNs }\end{array}$ & $\begin{array}{c}\% \\
\text { PSPMNs } \\
\text { PSPans } \\
\text { that are } \\
\text { TPH2+ }\end{array}$ & $\begin{array}{c}\text { TPH2+ } \\
\text { cells } \\
\text { (total } \\
\text { cells) }\end{array}$ \\
\hline dDR & 2 & 13 & 15 & $24(652)$ \\
cDR & 3 & 12 & 25 & $21(505)$ \\
vlPAG & 6 & 84 & 7 & $12(615)$ \\
vDR & 9 & 19 & 47 & $30(417)$ \\
vlDR & 15 & 75 & 20 & $11(287)$ \\
PPy & 12 & 51 & 24 & $6(391)$ \\
RPa & 7 & 15 & 47 & $12(829)$ \\
ROb & 27 & 102 & 26 & $5(296)$ \\
dGiA & 12 & 71 & 17 & $12(306)$ \\
vGiA & 21 & 37 & 57 & $19(273)$ \\
RMg & 23 & 97 & 24 & \\
\hline
\end{tabular}

Estimates of the total number of cells per section in each nucleus was derived from cresyl violet-stained sections, indicated in parentheses. Numbers represent totals from all animals normalized to the number of sections used to sample through each nucleus per animal.

per animal.
cDR, caudal dorsal raphe; dDR, dorsal subdivision of dorsal raphe; dGiA, dorsal gigantocellular nucleus pars alpha; PPy, parapyramidal cell group; RMg, raphe magnus $\mathrm{ROb}$, raphe obscurus; RPa, raphe pallidus; vDR, ventral subdivision of dorsal raphe; vGiA, ventral gigantocellular nucleus pars alpha; vlDR, ventrolateral dorsal raphe.

onstrated by the labeling in the spinal cord. Injections of PRV-BaBlu into the adrenal gland produced infection of ipsilateral sympathetic preganglionic neurons at midthoracic levels. This distribution of putative adrenal sympathetic preganglionic neurons is in close agreement with previous studies that demonstrated that these neurons are distributed from T4 to T12 in the spinal cord (Strack et al., 1989; Li et al., 1992; Joshi et al., 1995). Likewise, we detected PRV-152-infected somatic motoneurons at ipsilateral mid-lumbar spinal levels, which most likely represent gastrocnemius motoneurons since these cells were detected in the same location in previous investigations (Hashizume et al., 1988; Kanda et al., 1989; Kerman et al., 2003). Furthermore, we can be confident of the effectiveness of the surgical sympathectomy procedure since we did not observe infection with PRV-152 in the intermediolateral cell column in the same animals that showed robust infection of gastrocnemius motoneurons, which is also consistent with our past findings (Kerman et al., 2003, 2006).

We found considerable overlap between the distribution of TPH2-positive cells and PSPMNs. The distribution of TPH2-expressing PSPMNs differed along the rostrocaudal extent, with peaks in the rostral medulla and at the pontomedullary junction. Likewise, the distribution of these cells differed by nuclei so that $\mathrm{ROb}, \mathrm{RMg}$, and GiA contained the greatest numbers of triple-labeled neurons. The fraction of PSPMNs that were TPH2-positive also differed by nuclei. Interestingly, within GiA there was a difference in the location of triple-labeled cells in the dorsoventral extent, with a much greater percentage of such cells located within its ventral compartment. This is consistent with the recent findings of Toth et al. (2006), who found a differential distribution of serotonergic neurons that innervate the tail in this region. Those authors demonstrated that presympathetic serotonergic cells that innervate the tail are preferentially distributed toward the ventral edge of the ventromedial medulla, with large numbers located just dorsal to the pyramids (Toth et al., 2006). This finding is in agreement with our data that indicate that a large fraction of serotonergic PSPMNs are located 
within ventral $\mathrm{GiA}$ as well as with studies that used monosynaptic tracers and found preferential distribution of spinally projecting serotonergic neurons in the ventral GiA (Skagerberg and Björklund, 1985; Bowker and Abbott, 1990; Jones and Light, 1992).
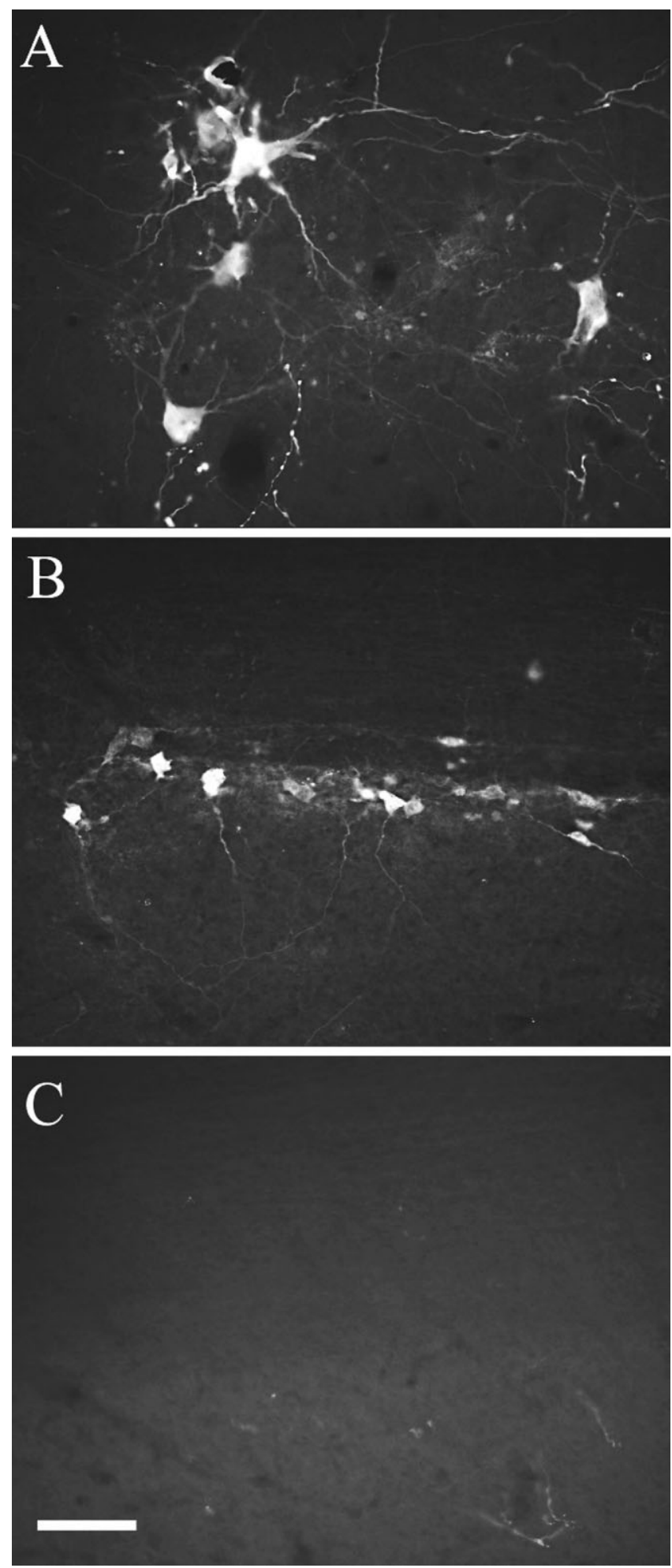

When interpreting our quantitative data it is important to keep in mind that these numbers represent estimates. To obtain more precise data with regard to the total number of TPH2-positive PSPMNs within different nuclei will require more extensive unbiased $3 \mathrm{D}$ sampling. Nonetheless, our current estimates suggest differences in the distribution of serotonergic PSPMNs within the brainstem.

Based on our findings, we hypothesize that these serotonergic PSPMNs likely project directly to the spinal cord, and that these projections probably collateralize to simultaneously innervate adrenal sympathetic preganglionic neurons in the thoracic spinal cord and gastrocnemius motoneurons in the lumbar spinal cord. This notion is supported by the fact that we detected TPH2-expressing PSPMNs at the earliest survival time examined in this study. We have previously reported the presence of double-infected neurons in the ventromedial medulla at an even earlier (96-hour postinjection into the gastrocnemius muscle) survival time point (Kerman et al., 2003). Furthermore, studies employing classical tract-tracing agents have demonstrated direct projections from the ventromedial medulla to the intermediolateral cell column as well as to the ventral horn of the spinal cord in different species (Martin et al., 1979, 1985; Zemlan et al., 1984; Holstege and Kuypers, 1987; Allen and Cechetto, 1994). Others have also demonstrated the presence of serotonergic terminals on motoneurons and sympathetic preganglionic neurons (Appel et al., 1986, 1987; Wu et al., 1993) as well as a high density of serotonergic fibers in the lumbar ventral horn and the intermediolateral cell column (Steinbusch, 1981). However, given the fact that we used a transsynaptic tracer we cannot conclude with certainty that these cells send direct projections to the spinal cord. Future work utilizing monosynaptic tracers will be required to test this hypothesis.

In contrast, relatively fewer triple-labeled neurons were found within the midbrain. Despite the presence of an appreciable number of double-infected neurons, a lesser fraction of PSPMNs was TPH2-positive, especially at the earlier survival times. Nonetheless, our data demonstrate a distinct clustering of TPH2-positive PSPMNs within the vlPAG and vlDR at the later survival times. It is unlikely that these neurons send direct projections to the spinal cord, since their presence is not detected until the later survival times. Instead, it is possible that these cells send projections to the ventral medulla to simultaneously regulate sympathetic and somatomotor functions. This notion is consistent with traditional tract-tracing experiments that have demonstrated projections from the ventral and ventrolateral periaqueductal gray to the ventromedial medulla (Beitz et al., 1983; Van Bockstaele et al., 1991; Beitz, 1995; Farkas et al., 1998).

Fig. 4. Labeling in the spinal cord following PRV injections into gastrocnemius muscle and adrenal gland. In the same animal we observed PRV-152-infected somatic motoneurons at L4 spinal level ipsilateral to the injected side (A) as well as PRV-BaBlu-infected sympathetic preganglionic neurons in the ipsilateral intermediolateral cell column at T8 $(\mathbf{B})$. These neuronal populations correspond to the gastrocnemius motoneuron pool and adrenal sympathetic preganglionic neurons, respectively. Effectiveness of the surgical sympathectomy was confirmed by the absence of PRV-152-infected neurons in the intermediolateral cell column, an example at the ipsilateral T13 is shown $(\mathbf{C})$. Scale bar $100 \mu \mathrm{m}$. 

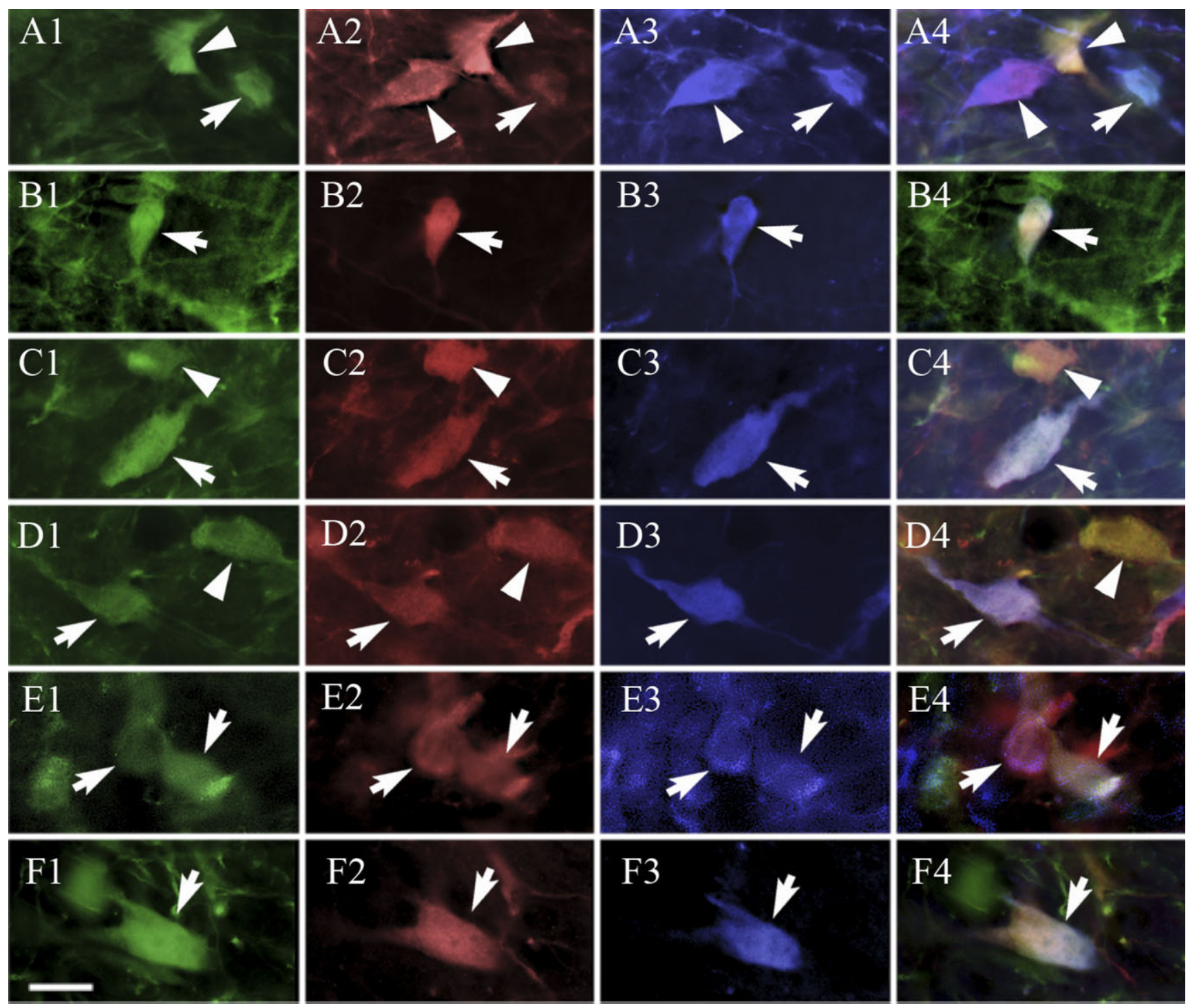

Fig. 5. Examples of colocalization of TPH2 with PRV-152 and PRV-BaBlu. Different panels represent distinct nuclei within medulla-pons and the midbrain. These include the parapyramidal cell group $(\mathbf{A})$, gigantocellular nucleus pars alpha $(\mathbf{B})$, raphe obscurus $(\mathbf{C})$, raphe magnus (D), raphe pallidus (E), and the ventrolateral periaq-

ueductal gray $(\mathbf{F})$. Neurons infected with PRV-152 (1) were also infected PRV-BaBlu (2) and/or expressed TPH2 (3). Merged images (of $1+2+3)$ are in panels 4 . Triple-labeled neurons are shown with arrows, while double-labeled neurons are indicated with arrowheads. Scale bar $=20 \mu \mathrm{m}$.

Taken together, our data demonstrate the presence of clusters of serotonergic PSPMNs within the rostral medulla and at the medullopontine junction. Previous studies have investigated the fraction of spinally projecting neurons from the ventromedial medulla that are serotonergic. These estimates have ranged from $30-$ 60\% (Skagerberg and Björklund, 1985; Jones and Light, 1992) of spinally projecting neurons that are serotonergic to over $90 \%$ of such cells (Bowker and Abbott, 1990). Our data (see Table 1) suggest that in $\mathrm{ROb}$ and $\mathrm{RMg}$ $\sim 20-30 \%$ of PSPMNs are serotonergic, while in $\mathrm{RPa}$ and ventral GiA this fraction is $\sim 40-60 \%$. These data may actually underestimate the true fraction of TPH2expressing PSPMNs since viral infection inhibits transcription of the host cell genome (Card, 2001). Nonethe-

less, these are heterogeneous nuclei that contain neurons of multiple phenotypes. For example, the ventromedial medulla has prominent expression of glutamic acid decarboxylase (GAD) (Stornetta and Guyenet, 1999), a key synthetic enzyme in the production of GABA, as well as vesicular glutamate transporters (Nakamura et al., 2004), suggesting that there are populations of glutamatergic and GABAergic cells in this region. Additionally, cells within the ventromedial medulla also express a number of peptidergic transmitters, including enkephalin, thyrotropin-releasing hormone, and substance P (Kerman et al., 2004). The possibility that the nonserotonergic PSPMNs within GiA express GAD, glutamate, and/or peptide neurotransmitters remains to be explored. 


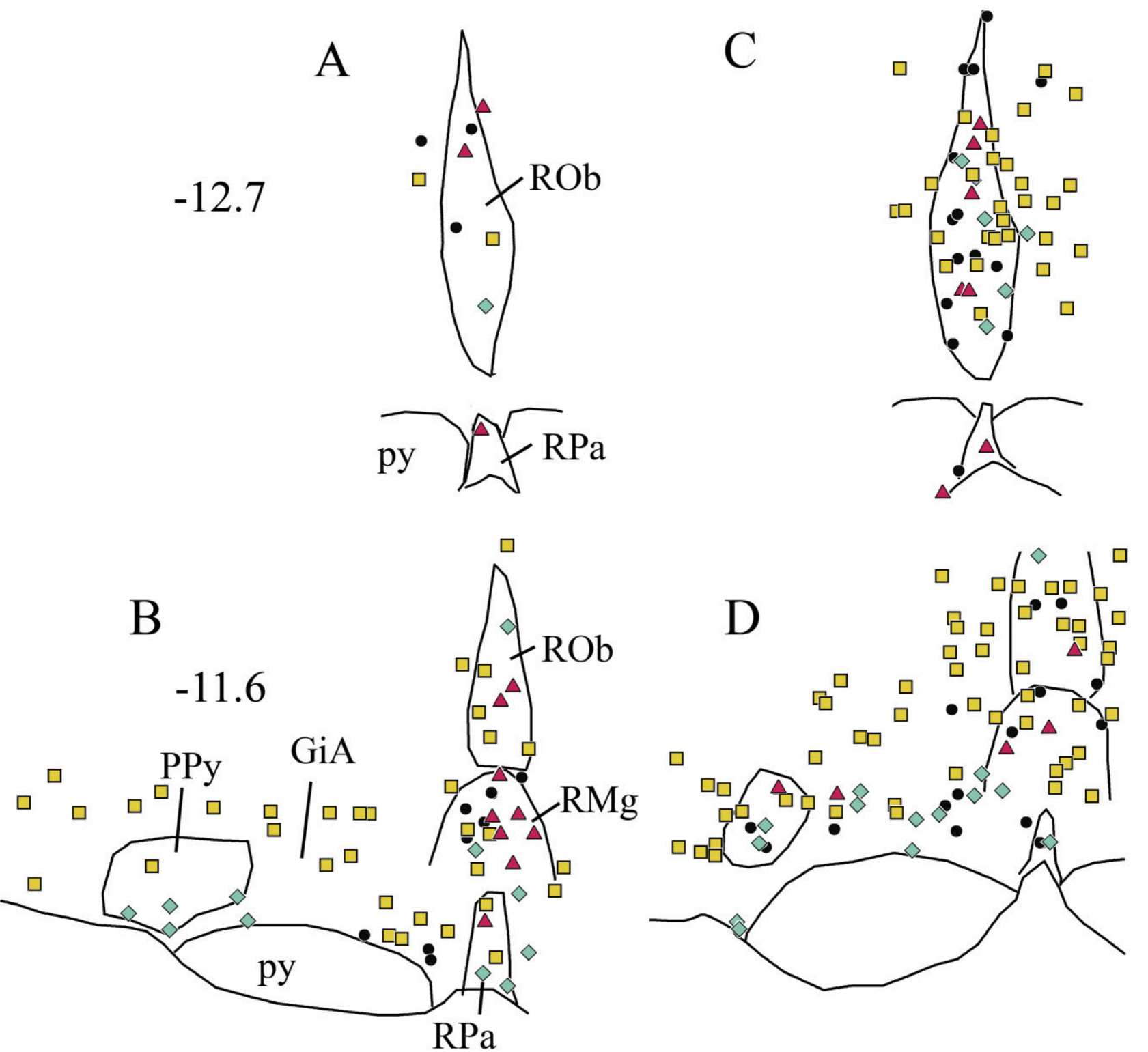

Fig. 6. Distribution of double- and triple-labeled neurons within the medulla. Anatomical landmarks were traced from original sections and locations of virus-infected cells were plotted onto these maps. Only one hemisection is presented from each level, but the pattern of labeling was symmetrical. Each symbol represents one neuron on the actual section. Yellow squares represent neurons coinfected with PRV-152 and PRV-BaBlu, black circles: neurons coinfected with PRV-152 and PRV-BaBlu that also express TPH2; red triangles: TPH2-containing neurons that are infected with PRV-
BaBlu; aqua diamonds: TPH2-containing neurons infected with PRV152. Panels on the left $(\mathbf{A}, \mathbf{B})$ are from animals that survived 122 and 97 hours following injections with PRV-152 and PRV-BaBlu, respectively. Panels on the right $(\mathbf{C , D})$ are from animals that survived 144 and 120 hours following injections with PRV-152 and PRV-BaBlu, respectively. Numbers on the left represent approximate distance in $\mathrm{mm}$ from bregma. py, pyramidal tract; $\mathrm{RPa}$, raphe pallidus; $\mathrm{ROb}$, raphe obscurus; PPy, parapyramidal area; GiA, gigantocellular nucleus pars alpha; $\mathrm{RMg}$, raphe magnus.
To determine whether the proportion of TPH2positive PSPMNs is identical to the proportion of cells that is serotonergic in each nucleus, we estimated the latter from cresyl violet-counterstained tissue. These estimates suggest that the fraction of cells in each nucleus that is serotonergic ranges from 5-33\%. These numbers are consistent with previous estimates, which found that $\sim 10-30 \%$ of the medullary raphe cells are serotonergic (Moore, 1981; Potrebic et al., 1994). These estimates also suggest that the number of TPH2positive PSPMNs is not simply a reflection of the fraction of serotonergic cells in each nucleus. For example, within the ventral subdivision of GiA, 57\% of PSPMNs are serotonergic, while only $12 \%$ of all cells are serotonergic (Table 1). Likewise, within $\mathrm{ROb}$ and $\mathrm{PPy}, 26 \%$ and $24 \%$ of PSPMNs are serotonergic, respectively, while the fraction of serotonergic neurons is $12 \%$ and $6 \%$, respectively (Table 1 ). Thus, within many of the 
A

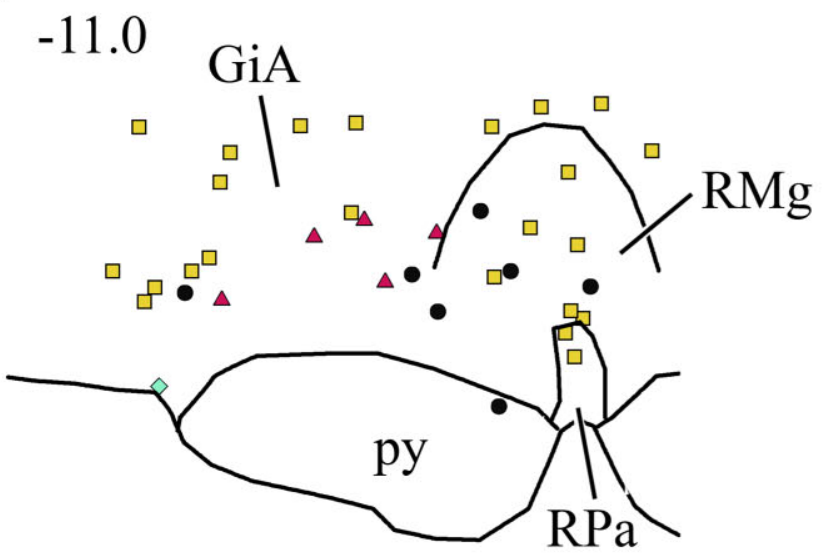

B

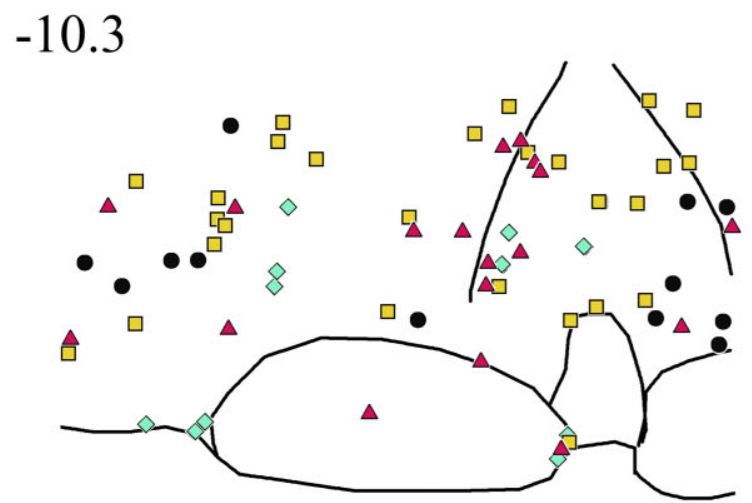

Fig. 7. Distribution of double- and triple-labeled neurons in the medulla. Presentation format and abbreviations are the same as in Figure 6. Panels on the left $(\mathbf{A}, \mathbf{B})$ are from animals that survived 122 and 97 hours following injections with PRV-152 and PRV-BaBlu,

nuclei examined, PSPMNs are more likely to be serotonergic than would be predicted by chance alone.

\section{Functional considerations}

Classically, the ventromedial medulla has been considered to be a pain modulatory area, since activation of this region can produce antinociception (Mason, 2001). This notion is supported by the connections of this region, which include neurons with direct projections to the dorsal horn (Mason, 2001). Our findings suggest that such antinociceptive neurons are intermingled with PSPMNs within the ventromedial medulla; thus, it is possible that activation of this region may coordinate somatomotor, autonomic, and sensory responses to acute pain stimuli. Such a scenario would include activation of PSPMNs to facilitate expression of appropriate somatomotor and autonomic responses as well as concurrent activation of the antinociceptive neurons for simultaneous pain modulation. This is supported by the fact that activation of the ventromedial medulla by injection of kainic acid or mor-
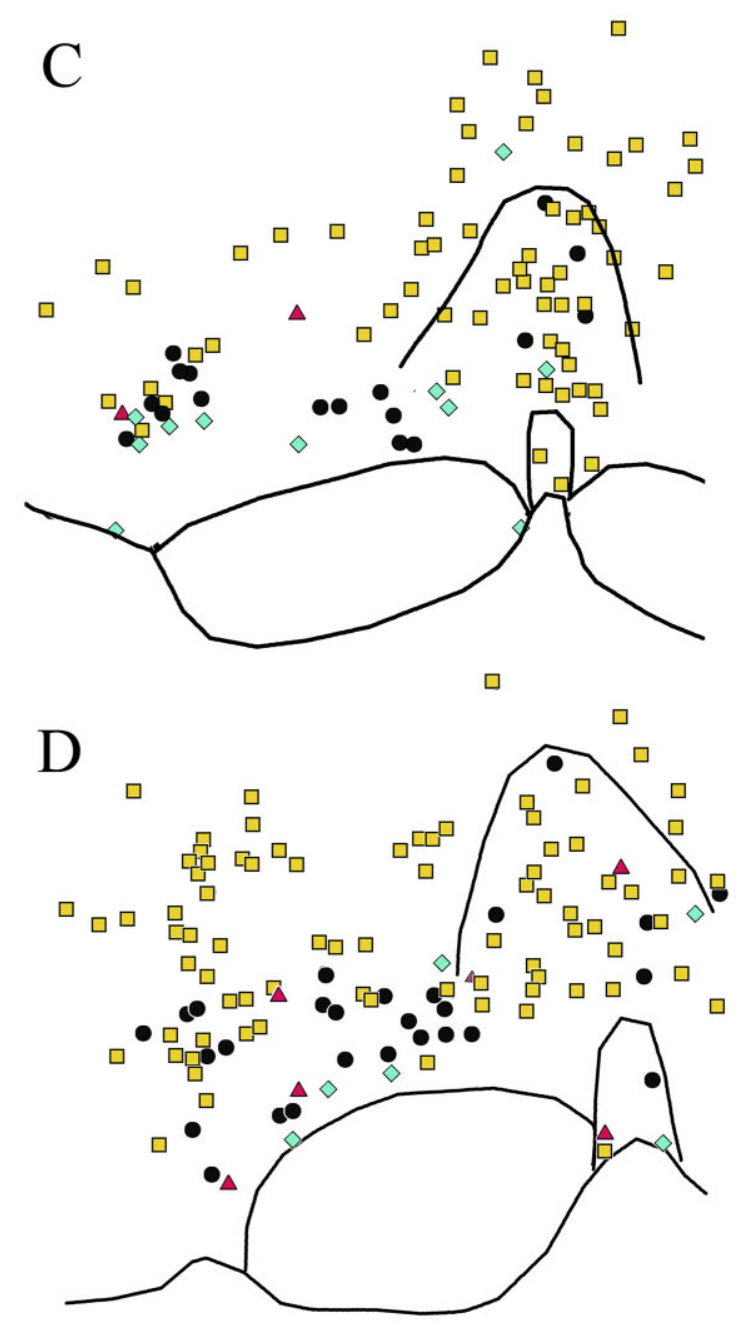

respectively. Panels on the right $(\mathbf{C , D})$ are from animals that survived 144 and 120 hours following injections with PRV-152 and PRV-BaBlu, respectively. Numbers on the left represent approximate distance in $\mathrm{mm}$ from bregma. phine elicits immobility together with antinociception (Morgan and Whitney, 2000). Although autonomic parameters were not measured in that study, our data suggest that such manipulations may also lead to the secretion of adrenal catecholamines. It is also likely that serotonergic neurons of the ventromedial medulla contribute to antinociception since they project to the dorsal horn (Mason, 2005), and application of serotonin receptor antagonists in the ventromedial medulla attenuates antinociception evoked by ventromedullary stimulation (Hammond and Yaksh, 1984; Barbaro et al., 1985). However, this action may be dependent on the behavioral state, such as the phase of the sleep/wake cycle (Mason, 2001). Likewise, serotonergic neurons of the ventromedial medulla identified in the present study may act to coordinate somatomotor and sympathetic functions during responses to acute pain stimuli.

Another functional possibility is that the serotonergic PSPMNs are involved in mediating central responses to exercise. Results of studies in awake behaving cats sug- 

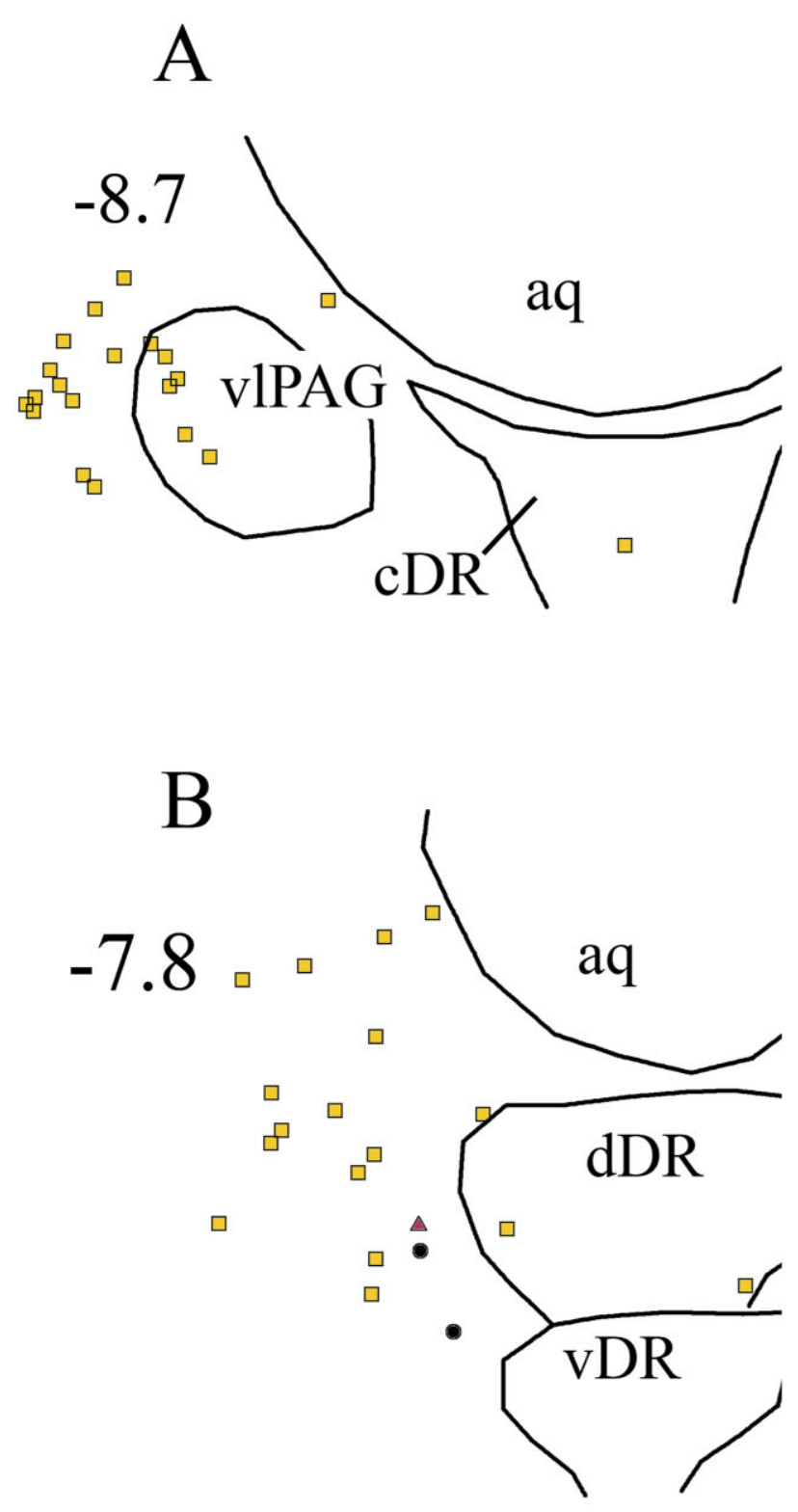

Fig. 8. Distribution of double- and triple-labeled neurons within the midbrain. Anatomical landmarks were traced from original sections and locations of virus-infected cells were plotted onto these maps. Symbols are the same as in Figure 6. A,B: Animals that survived 122 and 97 hours following injections with PRV-152 and

gest that a major role of the descending serotonergic system is to increase excitability of spinal motoneurons and to facilitate somatomotor output (Jacobs and Fornal, 1997). More recently, recordings from serotonergic neurons in the caudal raphe nuclei of awake locomoting cats suggest that the decreases in the firing of these neurons may be related to the onset of central fatigue (Fornal et al., 2006). Thus, the serotonergic PSPMNs may gate excitability of lumbar motoneurons and adrenal sympathetic

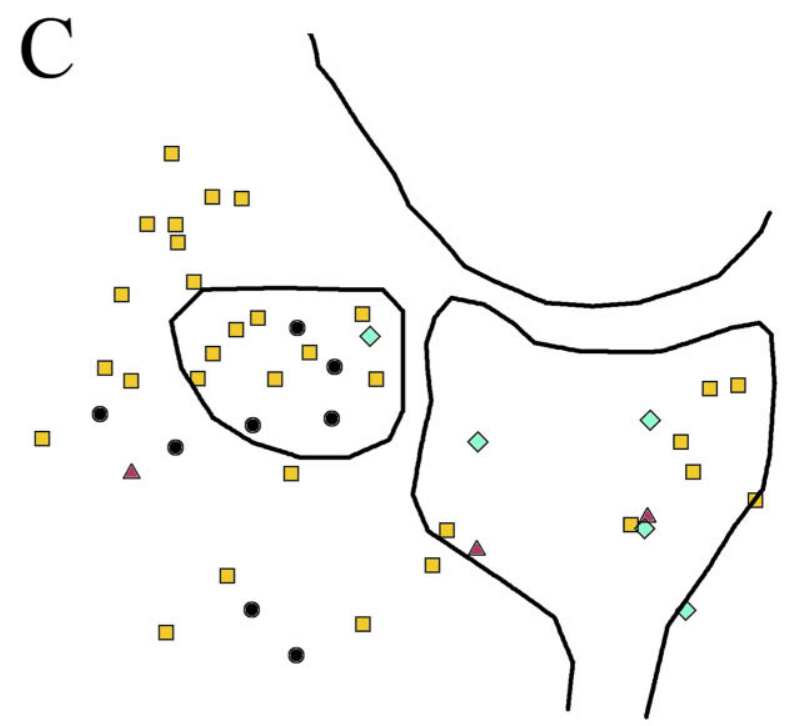

$\mathrm{D}$

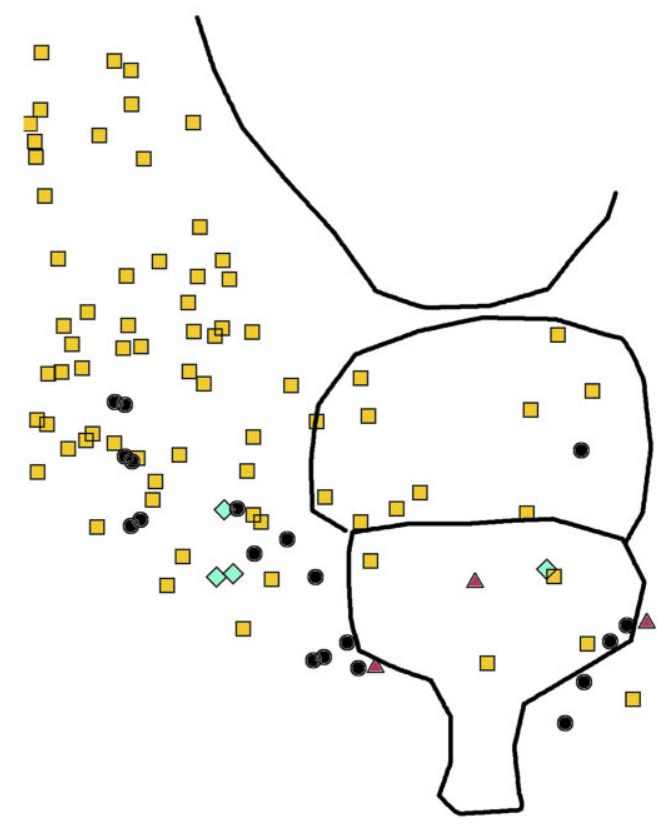

PRV-BaBlu, respectively. C,D: Animals that survived 144 and 120 hours following injections with PRV-152 and PRV-BaBlu, respectively. aq, central aqueduct; cDR, caudal dorsal raphe; $\mathrm{dDR}$, dorsal subdivision of the dorsal raphe; vDR, ventral subdivision of the dorsal raphe; vlPAG, ventrolateral periaqueductal gray.

preganglionic neurons to prevent excessive stress during exercise.

The serotonergic PSPMNs identified in the present study may also play a role in serotonin syndrome, an adverse reaction to intoxication with agents that lead to increased serotonin release such as selective serotonin reuptake inhibitors (Boyer and Shannon, 2005). This condition is often characterized by somatomotor disturbances such as spasms, shivering, and myoclonus as well as au- 
tonomic signs such as hypertension, tachycardia, and hyperthermia (Boyer and Shannon, 2005). This notion is consistent with the finding that disinhibition of the ventromedial medulla in lightly anesthetized rats causes increases in blood pressure, tachypnea, shivering, and an elevation in the temperature of brown adipose tissue $(\mathrm{Na}-$ son and Mason, 2004).

Thus, it is possible that under normal conditions serotonergic PSPMNs may mediate physiological responses to acute pain stimuli and exercise, while under pathological conditions they may mediate symptoms of serotonergic intoxication.

\section{ACKNOWLEDGMENTS}

The authors thank Dr. Lynn Enquist for the generous gift of viral stocks, and Drs. René Bernard, Sarah Clinton, Douglas Frost, and Lutz Slomianka for critical reading of an earlier version of the article. We also thank James Beals for help with preparing illustrations, and Sharon Burke, Jennifer Fitzpatrick, and Devin Rosenthal for excellent technical assistance.

\section{LITERATURE CITED}

Allen GV, Cechetto DF. 1994. Serotoninergic and nonserotoninergic neurons in the medullary raphe system have axon collateral projections to autonomic and somatic cell groups in the medulla and spinal cord. J Comp Neurol 350:357-366.

Appel NM, Wessendorf MW, Elde RP. 1986. Coexistence of serotonin- and substance P-like immunoreactivity in nerve fibers apposing identified sympathoadrenal preganglionic neurons in rat intermediolateral cell column. Neurosci Lett 65:241-246.

Appel NM, Wessendorf MW, Elde RP. 1987. Thyrotropin-releasing hormone in spinal cord: coexistence with serotonin and with substance $\mathrm{P}$ in fibers and terminals apposing identified preganglionic sympathetic neurons. Brain Res 415:137-143.

Barbaro NM, Hammond DL, Fields HL. 1985. Effects of intrathecally administered methysergide and yohimbine on microstimulationproduced antinociception in the rat. Brain Res 343:223-229.

Beitz AJ. 1995. Periaqueductal gray. In: Paxinos G, editor. The rat nervous system, 2nd ed. San Diego: Academic Press. p 173-182.

Beitz AJ, Shepard RD, Wells WE. 1983. The periaqueductal gray-raphe magnus projection contains somatostatin, neurotensin and serotonin but not cholecystokinin. Brain Res 261:132-137.

Billig I, Foris JM, Card JP, Yates BJ. 1999. Transneuronal tracing of neural pathways controlling an abdominal muscle, rectus, abdominis in the ferret. Brain Res 820:31-44.

Billig I, Foris JM, Enquist LW, Card JP, Yates BJ. 2000. Definition of neuronal circuitry controlling the activity of phrenic and abdominal motoneurons in the ferret using recombinant strains of pseudorabies virus. J Neurosci 20:7446-7454

Billig I, Hartge K, Card JP, Yates BJ. 2001. Transneuronal tracing of neural pathways controlling abdominal musculature in the ferret. Brain Res 912:24-32.

Bowker RM, Abbott LC. 1990. Quantitative re-evaluation of descending serotonergic and non-serotonergic projections from the medulla of the rodent: evidence for extensive co-existence of serotonin and peptides in the same spinally projecting neurons, but not from the nucleus raphe magnus. Brain Res 512:15-25.

Boyer EW, Shannon M. 2005. The serotonin syndrome. N Engl J Med 352:1112-1120.

Cannon WB. 1963. The wisdom of the body. New York: W.W. Norton.

Card JP. 2001. Pseudorabies virus neuroinvasiveness: a window into the functional organization of the brain. Adv Virus Res 56:39-71.

Card JP, Rinaman L, Lynn RB, Lee BH, Meade RP, Miselis RR, Enquist LW. 1993. Pseudorabies virus infection of the rat central nervous system: ultrastructural characterization of viral replication, transport, and pathogenesis. J Neurosci 13:2515-2539.

Demmin GL, Clase AC, Randall JA, Enquist LW, Banfield BW. 2001 Insertions in the gG gene of pseudorabies virus reduce expression of the upstream Us3 protein and inhibit cell-to-cell spread of virus infection. J Virol 75:10856-10869.

Enquist LW, Husak PJ, Banfield BW, Smith GA. 1998. Infection and spread of alphaherpesviruses in the nervous system. Adv Virus Res 51:237-347.

Farkas E, Jansen AS, Loewy AD. 1998. Periaqueductal gray matter input to cardiac-related sympathetic premotor neurons. Brain Res 792:179192.

Fornal CA, Martin-Cora FJ, Jacobs BL. 2006. "Fatigue" of medullary but not mesencephalic raphe serotonergic neurons during locomotion in cats. Brain Res 1072:55-61.

Hammond DL, Yaksh TL. 1984. Antagonism of stimulation-produced antinociception by intrathecal administration of methysergide or phentolamine. Brain Res 298:329-337.

Hashizume K, Kanda K, Burke RE. 1988. Medial gastrocnemius motor nucleus in the rat: age-related changes in the number and size of motoneurons. J Comp Neurol 269:425-430.

Hilton SM. 1982. The defence-arousal system and its relevance for circulatory and respiratory control. J Exp Biol 100:159-174.

Holstege G. 1995. The basic, somatic, and emotional components of the motor system in mammals. In: Paxinos G, editor. The rat nervous system, 2nd ed. San Diego: Academic Press.

Holstege JC, Kuypers HG. 1987. Brainstem projections to spinal motoneurons: an update. Neurosci 23:809-821.

Jacobs BL, Fornal CA. 1997. Serotonin and motor activity. Curr Opin Neurobiol 7:820-825.

Jänig W, McLachlan EM. 1992. Characteristics of function-specific pathways in the sympathetic nervous system. Trends Neurosci 15:475-481.

Jones SL, Light AR. 1992. Serotoninergic medullary raphespinal projection to the lumbar spinal cord in the rat: a retrograde immunohistochemical study. J Comp Neurol 322:599-610.

Jordan D. 1990. Autonomic changes in affective behavior. In: Loewy AD, Spyer KM, editors. Central regulation of autonomic functions. New York: Oxford University Press. p 349-366.

Joshi S, Levatte MA, Dekaban GA, Weaver LC. 1995. Identification of spinal interneurons antecedent to adrenal sympathetic preganglionic neurons using trans-synaptic transport of herpes simplex virus type 1 . Neurosci 65:893-903.

Kanda K, Sato H, Hashizume K, Yamada J. 1989. The effects of blocking nerve conduction on retrograde HRP labeling of rat motoneuron. Neurosci Lett 99:153-156.

Kerman IA, Enquist LW, Watson SJ, Yates BJ. 2003. Brainstem substrates of sympatho-motor circuitry identified using trans-synaptic tracing with pseudorabies virus recombinants. J Neurosci 23:46574666.

Kerman IA, Buck BJ, Watson SJ. 2004. Expression of neurotransmitterrelated genes in the rat ventral medulla investigated with laser capture microdissection (LCM) and RT-PCR. Society for Neuroscience Abstracts, Program No. 540.20. 2004 Abstract Viewer/Itinerary Planner. Washington, DC: Society for Neuroscience.

Kerman IA, Akil H, Watson SJ. 2006. Rostral elements of sympatho-motor circuitry: a virally mediated transsynaptic tracing study. J Neurosci 26:3423-3433.

Kim JS, Enquist LW, Card JP. 1999. Circuit-specific coinfection of neurons in the rat central nervous system with two pseudorabies virus recombinants. J Virol 73:9521-9531.

Langley JN. 1921. The autonomic nervous system. Cambridge, UK: W Heffer.

Li Y-W, Ding Z-Q, Wesselingh SL, Blessing WW. 1992. Renal and adrenal sympathetic preganglionic neurons in rabbit spinal cord: tracing with Herpes simplex virus. Brain Res 573:147-152.

Mancia G, Zanchetti A. 1981. Hypothalamic control of autonomic functions. In: Morgane PJ, Panksepp J, editors. Behavioral studies of the hypothalamus. New York: Marcel Dekker. p 147-202.

Martin GF, Humbertson AO, Laxson C, Panneton WM. 1979. Evidence for direct bulbospinal projections to laminae IX, X and the intermediolateral cell column. Studies using axonal transport techniques in the North American opossum. Brain Res 170:165-171.

Martin GF, Vertes RP, Waltzer R. 1985. Spinal projections of the gigantocellular reticular formation in the rat. Evidence for projections from different areas to laminae I and II and lamina IX. Exp Brain Res 58:154-162

Mason P. 2001. Contributions of the medullary raphe and ventromedial reticular region to pain modulation and other homeostatic functions. Annu Rev Neurosci 24:737-777. 
Mason P. 2005. Deconstructing endogenous pain modulations. J Neurophysiol 94:1659-1663.

McLean IW, Nakane PK. 1974. Periodate-lysine-paraformaldehyde fixative. A new fixation for immunoelectron microscopy. J Histochem $\mathrm{Cy}$ tochem 22:1077-1083.

Moore RY. 1981. The anatomy of central serotonin neuron systems in the rat brain. In: Jacobs BL, Gelperin A, editors. Serotonin neurotransmission and behavior. Cambridge, MA: MIT Press.

Morgan MM, Whitney PK. 2000. Immobility accompanies the antinociception mediated by the rostral ventromedial medulla of the rat. Brain Res $872: 276-281$.

Morrison SF. 2004. Central pathways controlling brown adipose tissue thermogenesis. News Physiol Sci 19:67-74.

Nakamura K, Matsumura K, Hubschle T, Nakamura Y, Hioki H, Fujiyama F, Boldogkoi Z, Konig M, Thiel HJ, Gerstberger R, Kobayashi S, Kaneko T. 2004. Identification of sympathetic premotor neurons in medullary raphe regions mediating fever and other thermoregulatory functions. J Neurosci 24:5370-5380.

Nason MW Jr, Mason P. 2004. Modulation of sympathetic and somatomotor function by the ventromedial medulla. J Neurophysiol 92:510-522.

Nestler EJ, Hyman SE, Malenka RC. 2001. Serotonin, acetylcholine, and histamine. In: Nestler EJ, Hyman SE, Malenka RC, editors. Molecular neuropharmacology: a foundation for clinical neuroscience. New York: MacGraw-Hill. p 191-211.

Patel P, Pontrello C, Burke S. 2004. Robust and tissue-specific expression of TPH2 versus TPH1 in rat raphe and pineal gland. Biol Psychiatry $55: 428-433$.

Paxinos G, Watson C. 1986. The rat brain in stereotaxic coordinates. San Diego: Academic Press.

Potrebic SB, Fields HL, Mason P. 1994. Serotonin immunoreactivity is contained in one physiological cell class in the rat rostral ventromedial medulla. J Neurosci 14:1655-1665.

Skagerberg G, Björklund A. 1985. Topographic principles in the spinal projections of serotonergic and non-serotonergic brainstem neurons in the rat. Neuroscience 15:445-480.

Smith BN, Banfield BW, Smeraski CA, Wilcox CL, Dudek FE, Enquist LW, Pickard GE. 2000. Pseudorabies virus expressing enhanced green fluorescent protein: a tool for in vitro electrophysiological analysis of transsynaptically labeled neurons in identified central nervous system circuits. Proc Natl Acad Sci U S A 97:9264-9269.

Standish A, Enquist LW, Miselis RR, Schwaber JS. 1995. Dendritic mor phology of cardiac related medullary neurons defined by circuit-specific infection by a recombinant pseudorabies virus expressing betagalactosidase. J Neurovirol 1:359-368.
Steinbusch HW. 1981. Distribution of serotonin-immunoreactivity in the central nervous system of the rat-cell bodies and terminals. Neuroscience 6:557-618.

Stornetta RL, Guyenet PG. 1999. Distribution of glutamic acid decarboxylase mRNA-containing neurons in rat medulla projecting to thoracic spinal cord in relation to monoaminergic brainstem neurons. J Comp Neurol 407:367-380.

Strack AM, Sawyer WB, Platt KB, Loewy AD. 1989. CNS cell groups regulating the sympathetic outflow to adrenal gland as revealed by transneuronal cell body labeling with pseudorabies virus. Brain Res 491:274-296.

Sutcliffe JG, de Lecea L. 2000. The hypocretins: excitatory neuromodulatory peptides for multiple homeostatic systems, including sleep and feeding. J Neurosci Res 62:161-168.

Toth IE, Toth DE, Boldogkoi Z, Hornyak A, Palkovits M, Blessing WW. 2006. Serotonin-synthesizing neurons in the rostral medullary raphe/ parapyramidal region transneuronally labelled after injection of pseudorabies virus into the rat tail. Neurochem Res 31:277-286.

Vahlne A, Nystrom B, Sandberg M, Hamberger A, Lycke E. 1978. Attachment of herpes simplex virus to neurons and glial cells. J Gen Virol 40:359-371.

Vahlne A, Svennerholm B, Sandberg M, Hamberger A, Lycke E. 1980 Differences in attachment between herpes simplex type 1 and type 2 viruses to neurons and glial cells. Infect Immun 28:675-680.

Van Bockstaele EJ, Aston-Jones G, Pieribone VA, Ennis M, Shipley MT. 1991. Subregions of the periaqueductal gray topographically innervate the rostral ventral medulla in the rat. J Comp Neurol 309:305-327.

Waldrop TG, Eldridge FL, Iwamoto GA, Mitchell JH. 1996. Central neural control of respiration and circulation during exercise. In: Rowell LB, Shepherd JT, editors. Handbook of physiology section 12: exercise: regulation and integration of multiple systems. New York: Oxford University Press. p 333-380.

Walther DJ, Peter JU, Bashammakh S, Hortnagl H, Voits M, Fink H, Bader M. 2003. Synthesis of serotonin by a second tryptophan hydroxylase isoform. Science 299:76.

Wu W, Elde R, Wessendorf MW. 1993. Organization of the serotonergic innervation of spinal neurons in rats. III. Differential serotonergic innervation of somatic and parasympathetic preganglionic motoneurons as determined by patterns of co-existing peptides. Neuroscience 55:223-233.

Zemlan FP, Behbehani MM, Beckstead RM. 1984. Ascending and descending projections from nucleus reticularis magnocellularis and nucleus reticularis gigantocellularis: an autoradiographic and horseradish peroxidase study in the rat. Brain Res 292:207-220. 